\title{
REUTILIZAÇÃO DE CONTÊINERES PADRÃO ISO NA CONSTRUÇÃO DE EDIFÍCIOS COMERCIAIS NO SUL DO BRASIL
}

\section{THE REUSE OF ISO CONTAINERS IN THE CONSTRUCTION OF COMMERCIAL BUILDINGS IN SOUTHERN BRAZIL}

\author{
Luana Toralles Carbonari ${ }^{1}$ \\ Centro Universitário Filadélfia de Londrina, Londrina, PR, Brasil, luanatcarbonari@gmail.com \\ Fernando Barth ${ }^{2}$ \\ Universidade Federal de Santa Catarina, Florianópolis, SC, Brasil, fernando.barth@ufsc.br
}

\section{Resumo}

Os contêineres marítimos, padronizados pela International Standard Organization (ISO), têm sido reutilizados em diversos países, como forma de racionalizar e agilizar a construção de edifícios. Após o final do seu ciclo de vida, esses contêineres podem ser reutilizados na construção por ainda apresentarem elevada capacidade estrutural e grande resistência às intempéries. Essa reutilização exige adequações a esse novo uso. Neste contexto, busca-se avaliar os principais parâmetros construtivos representativos dessas transformações e das adequações que se mostraram necessárias em três edificações comerciais, situadas na região sul do Brasil. A caracterização e análise do sistema construtivo com contêineres foram realizadas a partir de levantamentos de documentação, fotografias e entrevistas com projetistas e construtores. O preparo, a logística operacional e os procedimentos adotados nas transformações dos contêineres mostram-se eficazes e adequados para o seu uso nas três edificações comerciais analisadas. Os resultados obtidos mostram, em caráter indicativo, que os contêineres ISO, mediante rápidas transformações, aumentam a rapidez e a racionalização da construção. Por fim, esses contêineres, que apresentam grande potencial de uso na construção de edifícios, também podem reduzir os desperdícios e os impactos ambientais associados, fazendo com que esse sistema construtivo possa contribuir para edificações mais sustentáveis.

Palavras-chave: Reutilização. Contêiner ISO. Edificação. Construção.

\begin{abstract}
Shipping containers, standardized by the International Standard Organization (ISO), have been reused in several countries as a way to streamline and speed up the construction of buildings. After the end of its life cycle, these containers can be reused in the construction because they still present a high structural capacity and high weather resistance. However, this reuse requires adjustments to this new use. In this context, this paper aim to assess the main representative constructive parameters of the se transformations and adaptations which proved necessary in three commercial buildings located in southern Brazil. The characterization and analysis of the construction system with containers were taken from documentation, photographs and interviews with designers and builders. The preparation, operational logistic and procedures adopted in the transformation of containers are considered effective and appropriate for use in the three commercial buildings selected. The results show that ISO containers can increase the speed and the rationalization of construction by rapid changes. Finally, these containers, that show great potential for use in building construction, can also reduce waste and associated environmental impacts, making this building system suitable to sustainable buildings.
\end{abstract}

Keywords: Reuse. ISO Container. Building. Construction.

How to cite this article:

CARBONARI, Luana Toralles; BARTH, Fernando. Reutilização de contêineres padrão ISO na construção de edifícios comerciais no sul do Brasil. PARC Pesquisa em Arquitetura e Construção, Campinas, SP, v. 6, n. 4, p. 255-265, dez. 2015. ISSN 1980-6809. Disponível em: <http://periodicos.sbu.unicamp.br/ojs/index.php/parc/article/view/8641165>. Acesso em: 19 mar. 2016. doi:http://dx.doi.org/10.20396/parc.v6i4.8641165. 


\section{Introdução}

A indústria da construção civil consome muitos recursos naturais, gerando grande quantidade de resíduos da construção civil, que segundo Santos, Cândida e Ferreira (2010) representam cerca de 50\% da massa de resíduos sólidos urbanos. Este percentual não mostra tendências de diminuição, pois segundo dados da Associação de Empresas de Limpeza Pública e Resíduos Especiais (2013), foram produzidos cerca de 76 milhões de toneladas de resíduos sólidos urbanos no Brasil em 2013, sendo que 54\% deste valor corresponde a resíduos de construção civil. Uma das soluções construtivas que vem sendo adotada para atenuar esses efeitos é o uso de materiais reutilizados, prática que minimiza o impacto ambiental gerado. Uma dessas alternativas é a reutilização de contêineres ISO nas edificações.

O termo contêiner ISO é utilizado para designar os contêineres de carga que atendem as normas da International Organization for Standardization - ISO, conforme definido pela norma NBR ISO 668 (ABNT, 2000). Corbas (2012) mostra que o uso destes contêineres nas edificações, além de ser ambientalmente correto, tem como característica marcante uma obra limpa, gerando um mínimo de resíduos e economia de recursos naturais, inclusive na fundação, que no caso dos contêineres exige uma intervenção menos invasiva no terreno.

Os contêineres apresentam elevada resistência mecânica e grande durabilidade, pois o aço utilizado recebe tratamentos que melhoram seu desempenho frente às condições climáticas extremas. Slawik et al. (2010) destacam que os contêineres apresentam outras características que podem trazer benefícios à construção de edifícios, pois são pré-fabricados, modulares, compactos e podem ser transladados, instalados provisoriamente, facilmente empilhados e conectados entre si por meio de parafusos ou soldas.

De acordo com dados do World Shipping Council (2014), existem atualmente mais de dezoito milhões de contêineres ISO circulando pelo mundo. Cerca de 5\% deste total são descartados todos os anos, pois, segundo Araújo (2012), eles apresentam uma vida útil no transporte de cargas de dez a quinze anos. Após esse período, os contêineres perdem seu uso como elemento de transporte de mercadorias, acumulando-se em extensos depósitos não operacionais nas regiões portuárias.

O Brasil se destaca por possuir um setor portuário composto por trinta e sete portos públicos distribuídos ao longo de uma costa de 8,5 mil quilômetros. Segundo o Instituto de Logística e Supply Chain- ILOS (2013), o setor de transporte marítimo tende a crescer $7,4 \%$ ao ano na próxima década. Essa expansão possibilitará que o volume de contêineres no país atinja o equivalente a 14,7 milhões de TEU (Twenty Foot Equivalent Unit). O TEU é uma unidade de capacidade de carga equivalente a vinte pés usada para descrever a capacidade dos contêineres ISO, sendo definidas internacionalmente as dimensões básicas 2,44 m (8') de largura, 2,59 m (8,5') de altura e dois comprimentos mais conhecidos, que são de $6,06 \mathrm{~m}$ $\left(20^{\prime}=1 \mathrm{TEU}\right)$ e $12,19 \mathrm{~m}(40$ '= 2 TEU $)$.

Desse total, os portos sul do Brasil se destacam em movimentação de carga, podendo atingir na próxima década o equivalente a 3,2 milhões de TEU. Neste contexto, pode-se prever um aumento do número de contêineres descartados no país, gerando condições propícias para o desenvolvimento de um novo modo de construção, que pela grande oferta de produtos tende a baixar o seu custo.

Pode-se observar que a utilização de contêineres na construção tem aumentado nos últimos anos no Brasil, despertando o interesse de profissionais, empresas especializadas e instituições públicas e privadas. Como exemplo tem-se o seu uso em canteiros de obras, instalações provisórias, residências e edificações comerciais. Yazbek (2015) destaca que os contêineres têm sido mais utilizados em projetos comerciais devido à rapidez na execução da obra, possibilitando que o empreendimento seja concluído em poucas semanas. Este tipo de construção também pode servir para comércios situados em áreas alugadas, tornando possível que a edificação seja removida e instalada em outra localidade, desde que essa mobilidade esteja prevista na fase inicial do projeto. Além disso, a utilização dos contêineres ISO em edificações pode ser uma opção para áreas com restrições ambientais, onde não podem ser realizadas construções permanentes, que costumam causar grande impacto no terreno.

Observa-se uma tendência nacional no aumento e diversificação dos projetos com contêineres ISO reutilizados na região sul do país, direcionados em grande parte ao uso comercial. Essa tendência se deve principalmente aos benefícios que este tipo de construção proporciona para este uso, à crescente aceitação por parte da população, ao aumento do número de empresas e profissionais atuando nesse tipo de construção e também em função da disponibilidade destes produtos nos portos marítimos da região.

Deve-se observar, no entanto, que esses contêineres são projetados para o transporte de cargas e não foram feitos para serem habitados. Figuerola (2013) aponta que para serem utilizados nas edificações eles necessitam passar previamente por uma seleção e inspeção técnica para avaliar riscos de contaminação dos contêineres. Segundo Castilho (2014), devem ser avaliados o estado de conservação do piso, a perda de alinhamento dos 
contêineres, o amassamento em seu invólucro e principalmente a integridade da sua estrutura.

Após o processo de seleção dos contêineres é realizada a sua adaptação para atender às especificidades do projeto de arquitetura. Além disso, faz-se necessária uma avaliação dos aspectos construtivos, considerando questões como o transporte e a manipulação dos contêineres, pois os custos com o deslocamento porto-obra e a área necessária para a movimentação destes módulos podem elevar os custos da construção. A realização de recortes para portas e janelas também é necessária, tendo em vista que inicialmente os contêineres são providos de apenas uma abertura. Para tanto, segundo o Residential Shipping Container Primer (RSCP, 2014), devem ser feitos reforços estruturais quando forem realizadas grandes aberturas nas chapas dos contêineres, conforme o tipo de carregamento. Observa se também a necessidade de se criarem compartimentações e de se adicionarem materiais de isolamento e revestimentos no interior destes módulos. Para isso, deve-se verificar a adequação dos materiais, de modo a proporcionar melhorias no conforto da edificação, pois a envoltória de aço dos contêineres apresenta elevada condutibilidade térmica.

Neste contexto, o artigo busca avaliar os aspectos construtivos na reutilização de contêineres ISO em edificações comerciais na região Sul do Brasil. Para tanto, foi caracterizado o processo construtivo, a logística operacional e os materiais utilizados em três edificações selecionadas por meio da análise dos aspectos construtivos das obras. Essas análises foram realizadas a partir de documentação gráfica e fotográfica obtida a partir de visitas a campo e entrevistas com os projetistas e responsáveis pelas obras.

Por fim, os resultados foram avaliados por meio de análises comparativas, buscando a sistematização das informações e conhecimentos obtidos. O conjunto destas análises possibilita reflexões sobre os métodos utilizados na pesquisa, comparando os resultados e as particularidades de cada estudo de caso.

\section{Aspectos técnicos dos contêineres ISO}

Os contêineres ISO são construções metálicas préfabricadas constituídas por estrutura com perfis e chapas de aço patinável que apresenta elevada resistência à corrosão, comumente conhecido como aço Corten.

A estrutura do contêiner ISO é composta por quatro vigas inferiores e quatro superiores que se conectam por meio de pilares posicionados nos cantos, formando uma armação intertravada e rígida. Esses quatro montantes são providos de cantoneiras que auxiliam no apoio, manuseio e travamento do conjunto.
A envoltória do contêiner é formada pelo piso, que possui um trilho de conexão intermediário soldado às vigas inferiores e que serve de sustentação para as placas de compensado; pelo painel frontal, composto por uma porta de duas folhas equipada com dobradiças soldadas nos pilares de sustentação e pelos painéis laterais e superior, os quais são soldados nas vigas perimetrais, como ilustrado na Figura 1.

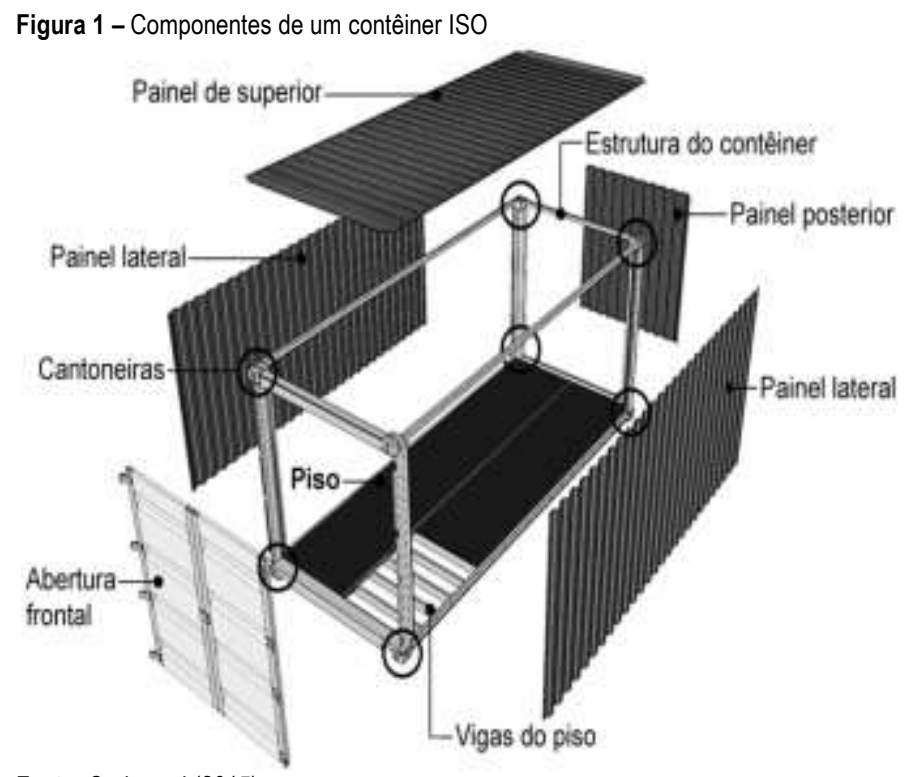

Fonte: Carbonari (2015)

Os painéis que compões as laterais e a cobertura do contêiner são feitos de chapa de aço trapezoidal com $2 \mathrm{~mm}$ de espessura, pois, segundo Slawik et al. (2010), são mais rentáveis e fáceis de reparar. Além disso, apresentam uma rigidez maior do que uma chapa totalmente plana e lisa.

A estrutura dos contêineres, reforçada em aço, é capaz de suportar aproximadamente dez vezes o próprio peso, o que possibilita que formem agrupamentos estáticos com oito unidades de altura no sentido transversal e com três unidades no sentido longitudinal. Isto é possível porque as cargas horizontais são suportadas e transmitidas das vigas para os pilares e são direcionadas para os pontos de apoio da estrutura. No entanto, é necessário assegurar que as cantoneiras estejam posicionadas uma acima da outra, garantindo assim a transmissão das cargas e a eficiência do conjunto.

Após o final da vida útil dos contêineres ISO, usados como elemento de transporte de mercadorias, é frequente o descarte dos modelos antigos, gerando um crescimento do descarte industrial portuário. Seu grande potencial de uso na construção civil se justifica devido à resistência do material e a sua versatilidade. Segundo Kotnik (2008), o caráter modular do sistema propicia flexibilidade ao projeto, pois pode agilizar o processo de montagem e desmontagem das edificações e possibilita a construção em etapas, de acordo com as necessidades dos usuários. 
De acordo com o RSCP (2014), os tipos de contêineres ISO mais utilizados nas construções são o tipo ISO 20' e 40 ' devido a grande versatilidade de uso. Uma alternativa para obter pé-direito maior nas construções arquitetônicas é a utilização do contêiner High Cube 40', que apresenta as mesmas dimensões do contêiner ISO 40', porém com uma altura externa de $2,89 \mathrm{~m}$.

Apesar dos aspectos positivos da utilização deste produto, os contêineres não foram feitos para serem habitáveis. A reutilização dos contêineres na construção de edifícios envolve, segundo Araújo (2012), o licenciamento ambiental, a desinfecção e o teste de radioatividade para poder identificar sua procedência e que tipo de material foi previamente transportado. Após a seleção dos contêineres é realizada a sua adaptação de acordo com as características do projeto arquitetônico. Além disso, faz-se necessária uma avaliação dos aspectos construtivos, que interferem na produção das edificações e nas diversas etapas da construção.

\section{Aspectos construtivos dos contêineres}

Neste item são apresentados os principais aspectos relacionados com a seleção, a logística operacional, o processo construtivo e os materiais utilizados em edificações com contêineres ISO reutilizados. Estes aspectos são posteriormente analisados nos três estudos de caso selecionados por Carbonari (2015).

A seleção dos contêineres costuma acontecer no terminal de contêineres, onde, segundo Castilho (2014), é verificada a existência de resíduos químicos e o estado de conservação do contêiner. Posteriormente, os contêineres são desamassados e são removidos os adesivos e outros elementos que possam interferir na pintura.

Para a utilização dos contêineres na construção de edifícios, segundo a empresa Delta Containers (2014), também é necessário conhecer a legislação vigente no local, assim como suas restrições, tais como: pé direito mínimo, áreas mínimas, etc. A documentação necessária para a liberação do projeto deve ser providenciada junto a Prefeitura local, etapa em que são obtidos também os alvarás e licenças.

O custo final da obra engloba, de modo geral, o valor dos contêineres, das transformações realizadas em sua envoltória, do frete e descarregamento, dos acabamentos e revestimentos utilizados interna e/ou externamente, além da instalação de mobiliário adequado ao seu uso.

$\mathrm{Na}$ utilização dos contêineres para a construção de edifícios deve-se considerar o tipo de transporte e o equipamento de manipulação, pois, segundo Slawik et al. (2010), os custos com o deslocamento porto-obra e o tempo de montagem podem encarecer a construção. $\mathrm{O}$ maquinário usado para o manuseio e transporte dos módulos também pode interferir no fluxo viário próximo ao terreno e na concepção do plano do canteiro de obras, pois necessita de um grande espaço para sua movimentação. $\mathrm{O}$ transporte pode ser realizado com a utilização de um caminhão convencional e o descarregamento com guindaste ou caminhão tipo Munck.

As fundações para os contêineres dependem da geometria do projeto, da temporalidade da obra e das propriedades geofísicas do terreno, considerando a declividade, a drenagem e a instabilidade do solo. Em geral os contêineres devem ser fixados na fundação pelas quatro cantoneiras inferiores, utilizando uma peça metálica ajustável cuja altura pode ser nivelada, impedindo que a edificação tenha movimentações pela ação do vento. Os tipos de fundação mais utilizados são o sistema de radier, as vigas baldrames e, na maioria das vezes, as sapatas isoladas de concreto.

A movimentação e o apoio dos contêineres devem ser realizados apenas pelas cantoneiras, que se encontram nos oito vértices dos contêineres. Segundo o RSCP (2014), a rigidez da estrutura do contêiner possibilita seu empilhamento em até oito unidades sem que a sua integridade seja comprometida. De acordo com Figuerola (2013), as aberturas de portas e janelas com medidas superiores a $1 / 3$ do comprimento do contêiner exigem reforços estruturais. Segundo Slawik et al. (2010), o acoplamento de unidades pode ser feito por ligações permanentes do tipo solda ou por ligações reversíveis com parafusamento.

Os contêineres normalmente chegam à obra parcialmente adaptados, com aberturas recortadas, molduras soldadas, que substituem os contramarcos, e instalações técnicas embutidas, pois a maioria das empresas que vendem os contêineres têm os equipamentos necessários para fazer essas modificações. Os recortes devem ser executados com precisão para permitir a colocação de esquadrias e geralmente são realizados com máquinas de corte a plasma. Este equipamento utiliza a eletricidade para aquecer o ar em plasma, que é direcionado para o metal e permite cortá-lo. Os requadros das aberturas devem ser realizados com o mesmo material do contêiner, pois ligas metálicas diferentes podem levar a corrosão de um dos metais empregados. Depois de realizadas as aberturas e os recortes nos contêineres é feita a limpeza para a remoção de sujeira e/ou óleo e após isso os mesmos são pintados externamente.

A compartimentação e os revestimentos internos, segundo o RSCP (2014), devem ser preferencialmente realizados após o nivelamento e estabilização dos contêineres. As soluções mais frequentes usam placas de gesso acartonado com quadros de madeira ou de aço. Essas soluções possibilitam que as instalações elétricas, hidrossanitárias e as camadas de isolamento térmico localizem-se entre os 
revestimentos internos e as paredes externas, facilitando a montagem. Como revestimentos internos, também podem ser utilizados o Medium Density Fiberboard (MDF), o Oriented Strand Board (OSB) e os painéis de argamassa armada. Pode-se manter o material original do piso de compensado naval ou acrescentar outros revestimentos, como a cerâmica, o piso laminado emborrachado, a madeira, o piso vinílico, dentre outros. Além disso, entre o piso original e o novo pode ser aplicada uma camada de isolamento térmico.

Externamente os revestimentos mais frequentemente utilizados são os painéis de argamassa armada, chapas laminadas, lambris de madeira tipo siding, painéis fenólicos, entre outros. Com relação à proteção da cobertura podem ser utilizados recobrimentos como madeira, vegetação ou polímeros. Além disso, pode ser adicionada uma nova cobertura aos contêineres ou deck para o terraço jardim. Neste caso deve ser feita uma estrutura secundária sobre a cobertura do térreo para poder instalar o piso do deck.

As instalações elétricas e hidrossanitárias podem ser feitas externamente ou internamente. No primeiro caso deve-se proteger das intempéries e no segundo caso, deve-se atentar para a diminuição da área dos ambientes internos. Um dos maiores desafios na utilização dos contêineres ISO em construções é assegurar o conforto, uma vez que a chapa de aço usada na sua envoltória não apresenta bom desempenho térmico. Para isso, podem ser utilizadas camadas de isolamento interna e externamente.

\section{Caracterização dos estudos de caso}

Três edificações, localizadas na região sul do Brasil, foram selecionadas a partir dos critérios de seleção dos estudos de caso propostos por Carbonari (2015). Os critérios de seleção utilizados são: edificações de uso comercial realizadas com dois a quatro contêineres ISO reutilizados; edificações localizadas na região sul do Brasil e construídas nos últimos cinco anos, pois configuram uma tipologia de construção recente no país.

O primeiro estudo de caso foi um lava rápido, situado no município de Londrina, Paraná, construído em aproximadamente quatro meses no ano de 2013. O segundo, um escritório de arquitetura, situado no município de Palhoça, Santa Catarina, construído em aproximadamente seis meses no ano de 2012. O terceiro, um comércio de calçados, situado no município de Portão, Rio Grande do Sul, construído em aproximadamente três meses no ano de 2014. A Figura 2 mostra a localização geográfica e as obras selecionadas.

O edifício Lava Rápido, de Londrina, está situado em um terreno com área de $688 \mathrm{~m}^{2}$ e possui uma área construída total de $193,25 \mathrm{~m}^{2}$, sendo composto por dois contêineres High Cube 40' no pavimento térreo e um contêiner High Cube 40' no pavimento superior. O acesso a este último contêiner é feito por meio de uma escada metálica descoberta. $\mathrm{O}$ acesso de veículos é feito por uma rampa e o de pedestres por uma escada que conduz ao deck de madeira. Os contêineres foram posicionados configurando um "L" no pavimento térreo e o contêiner superior foi rotacionado e apoiado em cima dos anteriores. Além disso, foram adicionadas coberturas metálicas: uma frontal para proteger o acesso principal, minimizar a radiação solar direta e realizar a conexão entre os contêineres e outra posterior, que também serve como cobertura da área de lavação de carros.

O edifício escritório, da cidade de Palhoça, está situado em um terreno com área de $600 \mathrm{~m}^{2}$ e possui uma área construída total de $85,10 \mathrm{~m}^{2}$, sendo composta por um contêiner High Cube 40' no pavimento térreo e outro no pavimento superior. Os contêineres foram posicionados configurando um "L", sendo o acesso ao contêiner superior feito por meio de uma escada helicoidal localizada no interior do edifício. Além disso, foi adicionado um deck de madeira no $2^{\circ}$ pavimento e uma área envidraçada no térreo por onde é feito o acesso ao escritório.

Por fim, o edifício da loja de calçados de Portão está situado em um terreno com área de $1855,77 \mathrm{~m}^{2}$ e possui uma área construída total de $119 \mathrm{~m}^{2}$, sendo composta por dois contêineres High Cube 40' no pavimento térreo e outros dois no pavimento superior. $\mathrm{O}$ acesso ao segundo pavimento é feito por meio de uma escada helicoidal posicionada no contêiner térreo frontal e por meio de uma escada em lance único situada nos fundos do contêiner térreo posterior.

A Figura 3 apresenta a implantação das três edificações e a Figura 4 mostra a configuração das plantas baixas do pavimento térreo e do $2^{\circ}$ pavimento do lava rápido de Londrina-PR

O contêiner térreo frontal do edifício Lava Rápido está dividido em três ambientes: a loja de conveniências e atendimento de clientes com 19,12 $\mathrm{m}^{2}$ de área, um banheiro para portadores de necessidades especiais com $4,53 \mathrm{~m}^{2}$ e um banheiro de uso misto com $2,82 \mathrm{~m}^{2}$. O contêiner térreo posterior está composto por três ambientes: o primeiro destinado aos serviços do lava rápido com área de $14,49 \mathrm{~m}^{2}$, o segundo destinado ao preparo dos veículos com área de $5,22 \mathrm{~m}^{2}$ e o terceiro que corresponde a uma área de serviço com área de 7,05 $\mathrm{m}^{2}$ que contem um toalete. $O$ contêiner superior comporta o escritório com área de $6,94 \mathrm{~m}^{2}$, a sala de reunião com área de $6,62 \mathrm{~m}^{2}$ e o estoque de materiais com 12,93 $\mathrm{m}^{2}$. 
Figura 2 - Localização dos estudos de caso: a) lava rápido em Londrina-PR, b) escritório na Palhoça-SC e c) loja de calçados em Portão-RS, respectivamente
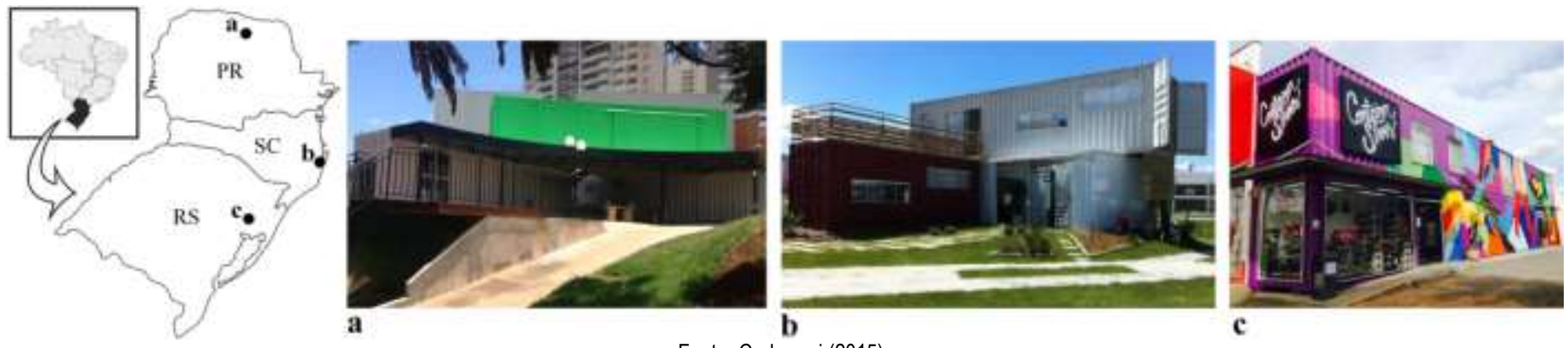

Fonte: Carbonari (2015)

Figura 3 - Implantação do Lava rápido em Londrina-PR, implantação do escritório na Palhoça-SC e implantação da loja em Portão-RS

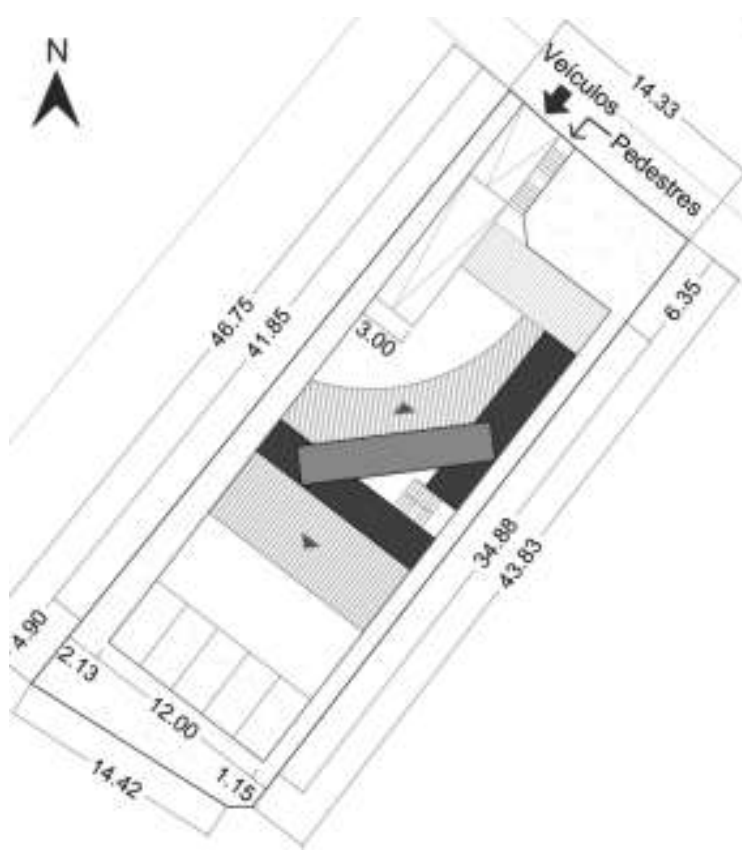

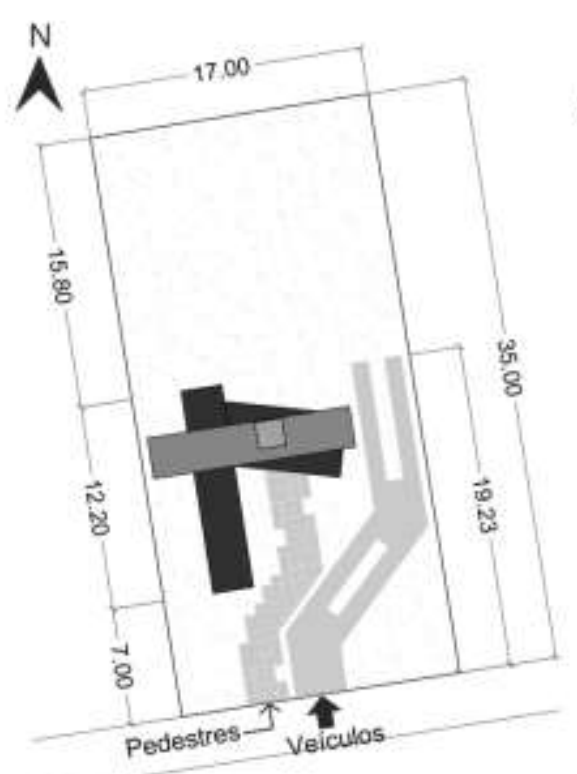

Fonte: Adaptado de Carbonari (2015)

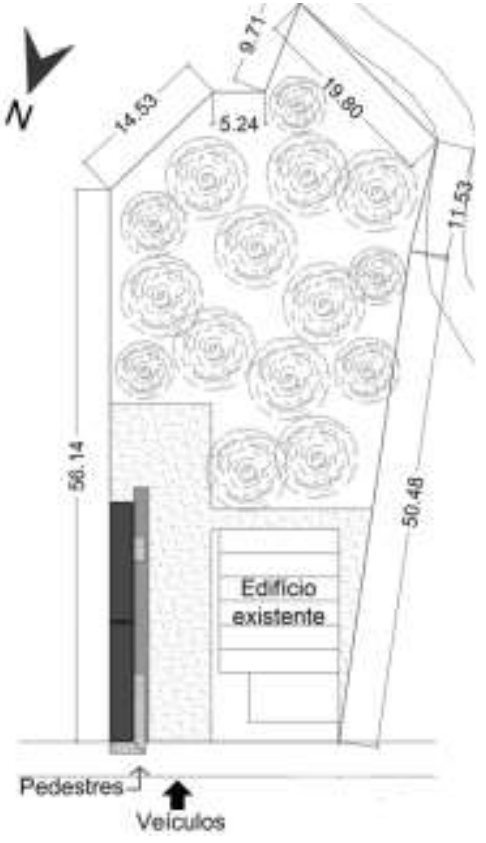

Figura 4 - Planta Baixa do térreo e do $2^{\circ}$ Pavimento do lava rápido de Londrina

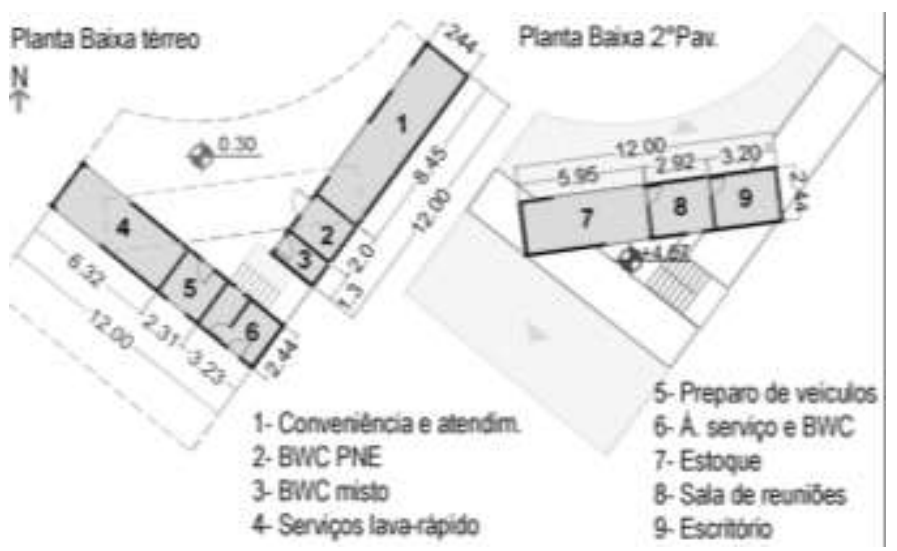

Fonte: Adaptado de Carbonari (2015) 
A Figura 5 mostra a configuração das plantas baixas do pavimento térreo e do $2^{\circ}$ pavimento do escritório de Palhoça-SC.

Figura 5 - Planta Baixa do térreo e do $2^{\circ}$ Pavimento do escritório da Palhoça

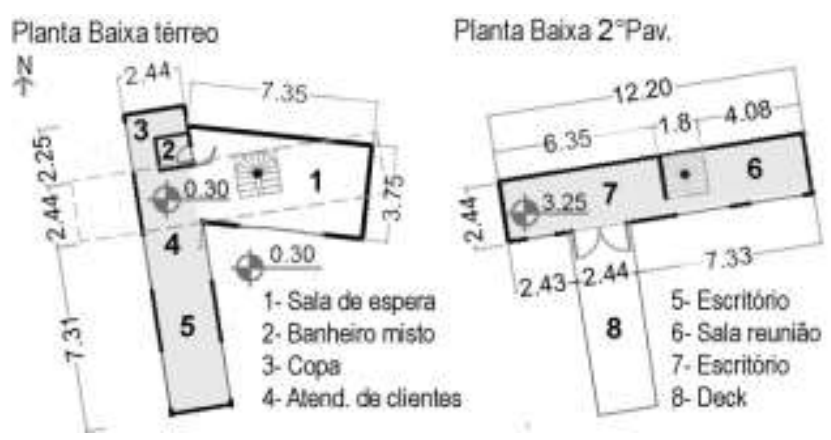

Fonte: Adaptado de Carbonari (2015)

O contêiner térreo está dividido em três ambientes: um escritório com área de 23,66 $\mathrm{m}^{2}$, um banheiro de uso misto com $1,54 \mathrm{~m}^{2}$ e uma copa com $2,82 \mathrm{~m}^{2}$. A área envidraçada térrea está composta por dois ambientes: o primeiro destinado a uma sala de espera com área de $14 \mathrm{~m}^{2}$ e o segundo destinado ao atendimento de clientes com área de $5,20 \mathrm{~m}^{2}$. Entre estas áreas está locada a escada helicoidal que dá acesso ao pavimento superior. O contêiner superior comporta a sala de reunião com área de $9,30 \mathrm{~m}^{2}$ e o escritório com área de $14,85 \mathrm{~m}^{2}$, por onde é feito o acesso ao deck de madeira externo.

A Figura 6 mostra a configuração das plantas baixas do pavimento térreo e do $2^{\circ}$ pavimento da loja de Portão-RS.

Figura 6 - Planta Baixa do térreo e do $2^{\circ}$ Pavimento da loja de Portão

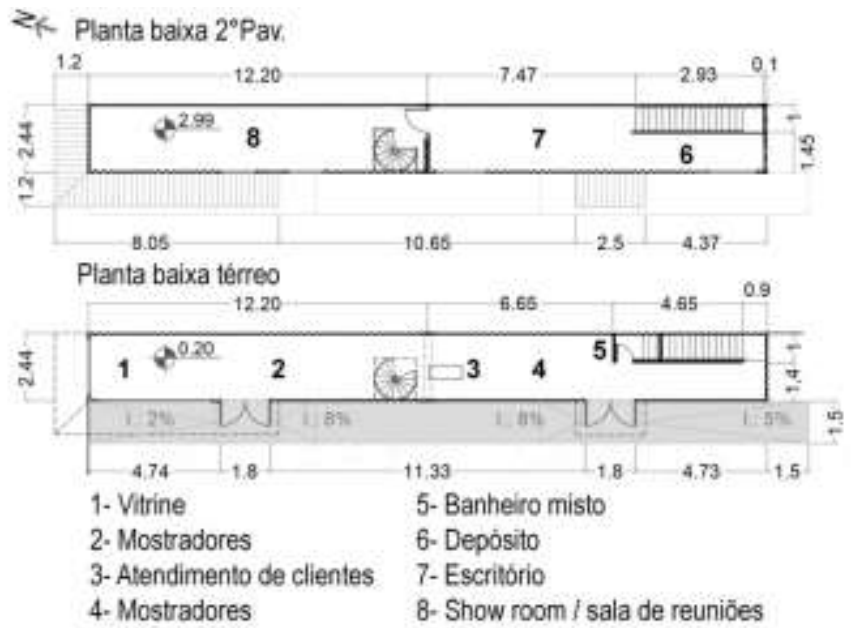

Fonte: Adaptado de Carbonari (2015)

Os dois contêineres térreos estão destinados à exposição dos calçados da loja e atendimento de clientes, comportando também um banheiro de uso misto com área de $1,65 \mathrm{~m}^{2}$ localizado nos fundos deste pavimento. Para fazer a conexão espacial entre os contêineres térreos foram retiradas as suas portas, deixando uma área interna livre de aproximadamente $50 \mathrm{~m}^{2}$. O contêiner superior frontal comporta uma sala de reunião e showroom com área de $25,44 \mathrm{~m}^{2}$ e o contêiner posterior está composto por um escritório com área de $16,7 \mathrm{~m}^{2}$ e um depósito com área de $8 \mathrm{~m}^{2}$.

\section{Aspectos construtivos dos casos}

A utilização dos contêineres na construção exige o estabelecimento de uma logística de implantação e manuseio, de modo a racionalizar o processo construtivo. Apesar de não implicar em grande impacto no preparo do terreno, pressupõe-se que as movimentações do terreno e preparo das fundações já se encontrem pré-dispostas no local.

No Quadro 1 são apresentados os seguintes aspectos construtivos dos estudos de caso: a) transporte $\mathrm{e}$ manipulação dos contêineres; b) fundações; c) ligações dos contêineres térreos com a fundação; d) ligações entre contêineres; e) aberturas para portas e janelas; f) materiais de revestimento dos pisos; g) materiais de revestimento das laterais e divisórias internas; h) materiais de revestimento das coberturas e i) instalações elétricas e hidrossanitárias.

\section{Análise comparativa dos casos}

As análises comparativas dos resultados obtidos nos estudos de caso tornaram possível verificar as variantes introduzidas em cada processo construtivo. Observa-se que estes resultados são de caráter indicativo, mostrando os principais aspectos do uso de contêineres em edificações comerciais na região Sul do Brasil.

Pôde-se verificar que as três edificações utilizaram o contêiner High Cube 40', que apresenta trinta centímetros a mais em sua altura quando comparado com o contêiner ISO 40', evidenciando assim a relevância do pé direito na escolha do tipo de contêiner. Em dois casos o contêiner superior foi rotacionado, criando espaços intermediários e uma composição mais dinâmica.

O número de contêineres utilizados nas edificações é bastante similar, estando distribuídos em dois pavimentos nos três casos. Observa-se que o estudo de caso que utiliza um maior número de contêineres não é o que apresenta maior área construída, pois neste caso a área limita-se ao espaço interno dos contêineres. De outra parte, a área construída na obra de Londrina está composta também por uma área gerada pelas coberturas metálicas adicionadas na edificação.

Nos três estudos de caso a área do terreno é superior à área construída, possibilitando espaços para estacionamento, o que normalmente se mostra necessário em edificações comerciais. O tempo de execução destas obras se limitou 
a poucos meses, evidenciando a rapidez deste tipo de construção quando comparado com uma construção convencional.

O transporte dos contêineres foi realizado nas três edificações com um caminhão convencional. Observa-se que nesta etapa do processo são frequentes os problemas com a altura da rede elétrica da rua, com a área necessária para manobrar o caminhão e com o fluxo de carros no local.
Pôde-se constatar que na fundação das três edificações foram utilizadas sapatas ou estacas de concreto executadas in loco, de modo a elevar de 10 a $30 \mathrm{~cm}$ o contêiner do solo. Os contêineres térreos foram apoiados na fundação sem elemento de fixação, sendo soldados em alguns pontos na área de contato com os contêineres do pavimento superior, para evitar movimentações ocasionadas pela ação do vento.

Quadro 1 -Quadro comparativo dos aspectos construtivos dos estudos de caso

\begin{tabular}{|c|c|c|c|}
\hline Aspectos & Lava rápido de Londrina-PR & Escritório de Palhoça-SC & Loja de Portão-RS \\
\hline $\begin{array}{l}\text { a) Transporte e } \\
\text { manipulação dos } \\
\text { contêineres }\end{array}$ & $\begin{array}{l}\text { Realizado com caminhão convencional e } \\
\text { com um caminhão grua para a } \\
\text { movimentação, que foi previamente } \\
\text { posicionado no terreno. Esta etapa foi } \\
\text { dificultada pela rede de alta tensão. }\end{array}$ & $\begin{array}{l}\text { Realizado com caminhão convencional e com } \\
\text { dois caminhões tipo Munck para a } \\
\text { movimentação. }\end{array}$ & $\begin{array}{l}\text { Realizado com caminhão convencional e } \\
\text { com dois caminhões tipo Munck para a } \\
\text { movimentação. Esta etapa foi operada a } \\
\text { noite para não atrapalhar o trânsito. }\end{array}$ \\
\hline b) Fundações & $\begin{array}{l}\text { Dez estacas de concreto tipo broca com } \\
\text { blocos de } 35 \text { x } 35 \mathrm{~cm} \text { com } 3 \mathrm{~m} \text { de } \\
\text { profundidade para cada contêiner térreo. }\end{array}$ & $\begin{array}{l}\text { Quatro sapatas isoladas de concreto de } 60 \mathrm{x} \\
60 \mathrm{~cm} \text { nas cantoneiras inferiores do contêiner } \\
\text { térreo e laje radier de concreto com } 10 \mathrm{~cm} \text { de } \\
\text { espessura na área envidraçada. }\end{array}$ & $\begin{array}{l}\text { Quatro sapatas corridas de concreto para } \\
\text { cada contêiner térreo. }\end{array}$ \\
\hline $\begin{array}{l}\text { c) Ligações dos } \\
\text { contêineres com } \\
\text { a fundação }\end{array}$ & $\begin{array}{l}\text { Realizadas sem elemento de fixação, } \\
\text { com contêineres } 15 \mathrm{~cm} \text { acima do solo } \\
\text { sobre camada de brita. }\end{array}$ & $\begin{array}{c}\text { Realizadas sem elemento de fixação, com } \\
\text { contêineres } 30 \mathrm{~cm} \text { acima do solo sobre } \\
\text { camada de brita. }\end{array}$ & $\begin{array}{l}\text { Realizadas sem elemento de fixação, com } \\
\text { contêiner frontal } 10 \mathrm{~cm} \text { acima do solo e } \\
\text { contêiner posterior } 30 \mathrm{~cm} \text { acima do solo } \\
\text { sobre camada de brita. }\end{array}$ \\
\hline $\begin{array}{l}\text { d) Ligações entre } \\
\text { contêineres }\end{array}$ & $\begin{array}{l}\text { Inicialmente o contêiner superior estava } \\
\text { apenas apoiado nos contêineres térreos, } \\
\text { sendo posteriormente soldado devido à } \\
\text { movimentação ocasionada pelo vento. }\end{array}$ & $\begin{array}{c}\text { Foram realizados alguns pontos de solda na } \\
\text { área de contato entre os contêineres térreo e } \\
\text { superior. }\end{array}$ & $\begin{array}{c}\text { Foram soldadas as cantoneiras dos } \\
\text { contêineres térreos com as dos contêineres } \\
\text { superiores devido à sua configuração } \\
\text { espacial. }\end{array}$ \\
\hline $\begin{array}{l}\text { e) Aberturas para } \\
\text { portas e janelas }\end{array}$ & $\begin{array}{l}\text { Recortadas com maçarico e } \\
\text { estruturadas após a montagem dos } \\
\text { contêineres. As chapas trapezoidais } \\
\text { recortadas foram reutilizadas nas portas } \\
\text { e janelas. Duas grandes aberturas dos } \\
\text { contêineres térreos apresentaram } \\
\text { deformações exigindo reforço estrutural. }\end{array}$ & $\begin{array}{l}\text { Recortadas com maçarico e estruturadas } \\
\text { previamente. As esquadrias metálicas foram } \\
\text { colocadas após a montagem dos contêineres. } \\
\text { Foi realizada também abertura no piso do } \\
\text { contêiner superior para a instalação da escada } \\
\text { helicoidal e no teto deste contêiner para } \\
\text { entrada de luz natural. }\end{array}$ & $\begin{array}{l}\text { Recortadas com máquina de corte a plasma } \\
\text { e lixadas com esmerilhadeira, sendo } \\
\text { estruturadas previamente. As esquadrias } \\
\text { metálicas foram instaladas após a } \\
\text { montagem dos contêineres. Foram } \\
\text { realizadas aberturas no piso dos } \\
\text { contêineres superiores e no teto dos } \\
\text { inferiores para a instalação das duas } \\
\text { escadas internas. }\end{array}$ \\
\hline $\begin{array}{l}\text { f) Materiais de } \\
\text { revestimento dos } \\
\text { pisos }\end{array}$ & $\begin{array}{l}\text { Internamente foi lixado e envernizado o } \\
\text { piso original e aplicado piso cerâmico no } \\
\text { banheiro. Externamente foi feito um } \\
\text { deck na parte frontal e aplicado piso } \\
\text { cimentado nas demais áreas. }\end{array}$ & $\begin{array}{l}\text { Internamente foi lixado e envernizado o piso } \\
\text { original e colocado piso de PVC na área } \\
\text { envidraçada. Externamente foi feito deck de } \\
\text { madeira na cobertura do contêiner inferior. }\end{array}$ & $\begin{array}{c}\text { Internamente foi lixado e envernizado o piso } \\
\text { original e aplicado piso vinílico no banheiro. } \\
\text { Externamente foi feita rampa e calçada } \\
\text { cimentada. }\end{array}$ \\
\hline $\begin{array}{l}\text { g) Materiais de } \\
\text { revestimento das } \\
\text { laterais e } \\
\text { divisórias } \\
\text { internas }\end{array}$ & $\begin{array}{l}\text { As laterais internas foram pintadas de } \\
\text { branco, recebendo revestimento } \\
\text { cerâmico no banheiro. As divisórias com } \\
10 \mathrm{~cm} \text { de espessura foram realizadas } \\
\text { com gesso acartonado. As laterais } \\
\text { externas dos contêineres inferiores } \\
\text { foram pintadas com esmalte sintético } \\
\text { antioxidante na cor branca e na cor } \\
\text { verde no contêiner superior. }\end{array}$ & $\begin{array}{l}\text { Nas laterais internas foi aplicada uma estrutura } \\
\text { em madeira revestida com gesso acartonado } \\
\text { com espessura de } 12,5 \mathrm{~mm} \text { e isolamento } \\
\text { térmico de lã de rocha com espessura de } 25 \\
\text { mm. As divisórias com } 10 \mathrm{~cm} \text { de espessura } \\
\text { foram realizadas com gesso acartonado. } \\
\text { Externamente as laterais do contêiner térreo } \\
\text { foram pintadas na cor vermelha e do superior } \\
\text { na cor branca. }\end{array}$ & $\begin{array}{l}\text { Nas laterais internas foi aplicada uma } \\
\text { estrutura metálica revestida com chapas } \\
\text { tipo MDF com espessura de } 12 \mathrm{~mm} \text { e } \\
\text { isolamento térmico de lã de polipropileno } \\
\text { com espessura de } 40 \mathrm{~mm} \text {. As divisórias do } \\
\text { banheiro têm o mesmo revestimento, sendo } \\
\text { pintadas com hidrofugante. As laterais } \\
\text { externas dos contêineres foram pintadas } \\
\text { com esmalte sintético na cor rosa médio. }\end{array}$ \\
\hline $\begin{array}{l}\text { h) Materiais de } \\
\text { revestimento das } \\
\text { coberturas }\end{array}$ & $\begin{array}{c}\text { Pintado internamente na cor branca. } \mathrm{Na} \\
\text { parte externa foi aplicada tinta que } \\
\text { apresenta propriedades de isolamento } \\
\text { térmico }\end{array}$ & $\begin{array}{l}\text { Estrutura em madeira revestida com gesso } \\
\text { acartonado com espessura de } 12,5 \mathrm{~mm} \text { e } \\
\text { isolamento térmico de lã de rocha com } \\
\text { espessura de } 25 \mathrm{~mm} \text {. Externamente foi feito } \\
\text { um deck de madeira na cobertura do contêiner } \\
\text { térreo e na cobertura do contêiner superior foi } \\
\text { aplicada uma tinta anticorrosiva na cor branca. }\end{array}$ & $\begin{array}{l}\text { Estrutura metálica revestida com chapas } \\
\text { tipo MDF com espessura de } 15 \mathrm{~mm} \text { e } \\
\text { isolamento térmico de lã de polipropileno } \\
\text { com espessura de } 40 \mathrm{~mm} \text {. } \\
\text { Externamente a cobertura foi pintada com } \\
\text { esmalte sintético na cor rosa médio. }\end{array}$ \\
\hline $\begin{array}{l}\text { i) Instalações } \\
\text { elétricas e } \\
\text { hidrossanitárias }\end{array}$ & $\begin{array}{l}\text { Colocadas internamente e deixadas } \\
\text { aparentes nas vedações e coberturas. }\end{array}$ & $\begin{array}{l}\text { Embutidas internamente nas vedações e } \\
\text { forros. }\end{array}$ & $\begin{array}{c}\text { Embutidas internamente nas vedações e na } \\
\text { cobertura foram utilizadas eletrocalhas para } \\
\text { a fiação e instalação das luminárias. }\end{array}$ \\
\hline
\end{tabular}

Fonte: Adaptado de Carbonari (2015) 
Foram observadas deformações nas laterais dos contêineres inferiores do Lava Rápido de Londrina, que ocorreram devido à aplicação de cargas fora dos pontos de içamento/carregamento, evidenciando a necessidade de um estudo prévio dos carregamentos e reforços adicionais. Como correção foi feito um reforço estrutural nas áreas debilitadas com tubos de aço de seção retangular de $10 \mathrm{x}$ $10 \mathrm{~cm}$, tipo Metalon.

Observa-se que as escadas foram locadas externa e internamente, sendo mais frequente o seu uso no interior do edifício, o que exige uma análise de layout e da circulação interna devido à largura limitada dos contêineres. Para locar as escadas internamente é necessário realizar um recorte no piso do contêiner superior, o que é dificultado pela existência de vigas metálicas que sustentam as chapas de compensado. Essas escadas foram soldadas e/ou parafusadas nos contêineres, sendo mais utilizadas as escadas metálicas. As aberturas dos contêineres foram recortadas e reforçadas previamente, devido à dificuldade de fazê-lo com os contêineres montados no local.

A instalação das esquadrias foi feita in loco nas três obras, de modo a evitar possíveis danos no transporte dos contêineres até o terreno. O piso original do contêiner foi mantido nos três casos, sendo apenas lixado e envernizado, decorrente da solicitação dos clientes. Internamente, dois dos estudos de caso optaram pela instalação de material isolante térmico e revestimentos de paredes e forros, deixando as instalações elétricas e hidráulicas embutidas nas laterais e no teto. Externamente os contêineres das três edificações foram lixados e pintados, mantendo o aspecto visual característico dos contêineres.

Por fim, apesar das melhorias realizadas nas envoltórias dos três estudos de caso fez-se necessário o uso de algum tipo de aparelho de resfriamento do ar para melhorar o conforto térmico no interior dos contêineres. No Lava Rápido de Londrina foi instalado um sistema de ventilação forçada no contêiner térreo frontal e nos outros dois empreendimentos foram instalados aparelhos de arcondicionado tipo Split.

\section{Conclusão}

A grande disponibilidade de contêineres ISO faz com que sua reutilização tenda a crescer nas edificações brasileiras nos próximos anos. Assim, o desenvolvimento de projetos que reaproveitem estes produtos mostra-se como uma alternativa econômica e sustentável para a construção de edifícios.

Como visto, os contêineres ISO são uma alternativa préfabricada de fácil movimentação que facilita a montagem das edificações, podendo minimizar os desperdícios de materiais e contribuir para a padronização e racionalização dos processos construtivos.

A fase exploratória desta pesquisa mostrou que a reutilização dos contêineres ISO apresenta uma diversidade de usos em projetos de arquitetura no sul do Brasil. A maior parte dos projetos observados é utilizada para edificações comerciais compostas por poucos contêineres. Isso se deve porque esse tipo de construção pode reduzir significativamente o tempo de montagem do edifício, permitindo que o empreendimento comece a funcionar em poucos meses. Além disso, esta modalidade de construção agrega flexibilidade ao projeto, possibilitando que a edificação seja transladada a outra localidade quando necessário.

Grande parte dos projetos com contêineres foi construída nos últimos cinco anos, o que evidencia o caráter atual desse tipo de construção e sinaliza uma tendência de reutilização dos contêineres em edificações nesta região. De outra parte, as particularidades e características das edificações com contêineres ISO mostraram a necessidade de uma avaliação da viabilidade econômica e funcional. Além disso, verificou-se a necessidade de uma análise de possíveis problemas estruturais e de contaminação química ou biológica.

Observou-se também que as aberturas para portas e janelas são necessárias para prover a funcionalidade dos espaços e melhorar o desempenho térmico dos contêineres, devendo ser preferencialmente realizadas em fábrica. De outro lado, a compartimentação, as instalações hidráulicas e elétricas, o material de isolamento térmico e os revestimentos externos e internos podem ser feitos no local após o nivelamento e a fixação dos contêineres no terreno.

Nos estudos de caso selecionados observou-se uma facilidade e rapidez no transporte, manipulação e montagem dos contêineres, sendo realizados com caminhão convencional e caminhão tipo Munck. Entretanto, mostrou-se necessária a verificação da acessibilidade dos meios de transporte e movimentação no terreno, avaliando o fluxo de automóveis no local, a altura da rede elétrica de alta tensão e o espaço disponível para a manobra e movimentação dos contêineres.

Os tipos de fundações adotados nas três edificações foram relativamente simples e não causaram grandes impactos no terreno, sendo realizados de modo a elevar os contêineres térreos alguns centímetros do solo. Esses contêineres foram apoiados na fundação sem elemento de fixação, o que facilita a sua futura remoção caso seja necessário. A deformação excessiva observada nas laterais dos contêineres inferiores do primeiro estudo de caso evidencia a necessidade de uma análise prévia dos carregamentos e reforços adicionais nos contêineres. 
Na maioria dos estudos de caso, as aberturas de portas e janelas e a pintura externa dos contêineres foram feitas antes da montagem dos mesmos, devido às dificuldades de fazê-lo após estarem fixados no local. Por outra parte, as instalações das esquadrias, dos materiais de isolamento e revestimento interno e das instalações hidráulicas e elétricas foram realizadas in loco, de modo a evitar possíveis danos durante o transporte.

Externamente não foram adicionados revestimentos nas chapas metálicas, mantendo o aspecto visual característico dos contêineres ISO nas edificações. Apesar das melhorias realizadas nas envoltórias dos três estudos de caso fez-se necessário o uso de algum tipo de aparelho de condicionamento do ar.

De modo geral, observou-se que os principais pontos positivos na construção com contêineres concentram-se na versatilidade para usos comerciais, facilidade na movimentação e montagem no terreno, na sua flexibilidade compositiva e construtiva, caracterizada por fundações simples que facilitam uma futura remoção. Por outro lado, a reutilização dos mesmos exige cuidados na sua seleção e mão de obra especializada para realizar as adaptações, além de exigir reforços estruturais quando são realizadas grandes aberturas na sua envoltória. Além disso, é necessária uma avaliação da viabilidade econômica e funcional antes de se iniciar o projeto do edifício e as transformações dos contêineres.

Por fim, pode-se constatar que existe uma crescente utilização dos contêineres nas construções comerciais no sul do Brasil e que a sua reutilização pode apresentar resultados satisfatórios quanto aos usos propostos. Entretanto, observou-se que as principais dificuldades técnicas e construtivas estão relacionadas com a falta de conhecimento e experiência na realização de adequações nos contêineres, pois é um tipo de construção relativamente recente no sul do Brasil. Alguns dos principais problemas encontrados estão relacionados com a falta de uma área para movimentação e manobra adequada na manipulação dos contêineres, a escolha de materiais mais eficazes para melhorar o conforto térmico no interior das edificações e as deformações na estrutura por falta de uma análise prévia dos carregamentos e de reforços adicionais.

A pesar de este estudo tratar de um número limitado de edificações com contêineres, os resultados sinalizam que a reutilização de contêineres ISO apresenta viabilidade técnica e adequação aos fins propostos, indicando um grande potencial de uso na construção, o que pode contribuir para um incremento na racionalização e na sustentabilidade das edificações brasileiras.

\section{Referências}

ABNT - ASSOCIAÇÃO BRASILEIRA DE NORMAS TÉCNICAS. NBR ISO 668: contêineres Série 1: classificação, dimensões e capacidades. Rio de Janeiro, 2000. 68 p.

ASSOCIAÇÃO BRASILEIRA DE EMPRESAS DE LIMPEZA PÚBLICA E RESÍDUOS ESPECIAIS. Panorama dos resíduos sólidos no Brasil. 2013. ABRELPE. São Paulo. Disponível em: <http://www.abrelpe.org.br/>. Acesso em: 15 out. 2014.

ARAÚJO, C. Contêiner ganha espaço em projetos de construção civil. 2012. Disponível em:

<https://www.portosenavios.com.br/noticias/geral/13718-conteiner-ganha-espaco-em-projetos-de-construcao-civil >. Acesso em: 15 mai. 2014.

CARBONARI, L. T. Reutilização de contêineres ISO na arquitetura: aspectos projetuais, construtivos e normativos do desempenho térmico em edificações no sul do Brasil. 2015. 196 f. Dissertação (Mestrado em Arquitetura e Urbanismo) Universidade Federal de Santa Catarina, Santa Catarina, 2015.

CASTILHO, P. Delta containers na rede globo. 2014. Disponível em: 〈https://www.youtube.com/user/deltacontainers〉. Acesso em: 10 mar. 2015.

CORBAS, D. Entrevista Jornal Band. 2012. Disponível em: 〈http://www.youtube.com/watch?v=ZjUK3cvJPCU〉. Acesso em: 22 jul. 2013.

DELTA CONTAINERS. Construção usando containers: perguntas e respostas. 2014. Disponível em: <http://www.deltacontainers.com.br/projetos-especiais-containers-faq.html>. Acesso em: 22 ago. 2014.

FIGUEROLA, V. Contêineres de navio se tornam matéria-prima para a construção de casas. Téchne, São Paulo, dez. 2013. Disponível em: <http://techne.pini.com.br/engenharia-civil/201/conteineres-de-navio-se-tornam-materia-prima-para-a-construcaode-302572-1.aspx>. Acesso em: 10 mar. 2014. 
ILOS. Portos 2021: avaliação de demanda e capacidade do segmento portuário de contêineres no Brasil, 2012. Disponível em: $<$ http://www.abratec-

terminais.org.br/files/Portos2021_Avaliacao_de_Demanda_e_Capacidade_do_Segmento_Portuario_de_Conteineres_no_Brasil.pdf. > Acesso em: 19 mai. 2014.

KOTNIK, J. Container Architecture. Barcelona: Links, 2008. 253 p.

RSCP - RESIDENTIAL SHIPPING CONTAINER PRIMER. Everything about ISO cargo shipping containers. 2013.

Disponível em: <http://residentialshippingcontainerprimer.com/>. Acesso em: 03 mai. 2014.

SANTOS, H. N.; CÂNDIDA, A.; FERREIRA, T. K. S. Ações referentes a gestão de resíduos da construção civil em Araguari-MG. In: ENCONTRO NACIONAL DOS GEÓGRAFOS, 16, 2010, Porto Alegre. Anais eletrônicos... Porto Alegre.

SLAWIK, H. et al. Container Atlas: A Practical Guide to Container Architecture. Berlin: Gestalten, 2010.

WORLD SHIPPING COUNCIL. Containers. 2014. Disponível em: <http://www.worldshipping.org/about-theindustry/containers>. Acesso em: 15 abr. 2014.

YAZBEK, P. Containers viram casas com apelo moderno e preços atraentes. Exame, São Paulo: ed. abril, 2015. Disponível em: <http://exame.abril.com.br/seu-dinheiro/noticias/containers-viram-casas-com-apelo-moderno-e-precos-atraentes>. Acesso em: 15 abr. 2015.

\section{${ }^{1}$ Luana Toralles Carbonari 1}

Arquiteta e Urbanista. Mestre em Arquitetura e Urbanismo pela Universidade Federal de Santa Catarina. Endereço postal: Rua Caracas, 377, Londrina, PR, Brasil, 86050-070

\section{${ }^{2}$ Fernando Barth 2}

Engenheiro Civil. Doutor em Construções Arquitetônicas pela Universitat Politecnica de Catalunya. Endereço profissional: Departamento de Arquitetura e Urbanismo, Centro Tecnológico - UFSC, Florianópolis, SC, Brasil, 88040-900 